GEODESY AND CARTOGRAPHY

ISSN 2029-6991 print / ISSN 2029-7009 online

UDK 528.714

\title{
CHARACTERIZING CLOUD COVER AND SATELLITE REVISIT WITH CLOUD MASKS IN NORTH WEST ENGLAND
}

\author{
Ebenezer Yemi Ogunbadewa \\ Adekunle Ajasin University, P.M.B. 001, Akungba Ondo-State, Nigeria \\ E-mail: ogunbadewa202@yahoo.com
}

Received 28 December 2011; accepted 21 March 2012

\begin{abstract}
The aim of this study is to determine the availability of cloud-free images in relation to satellite revisit periods for the UK and in particular for the North West of England. Cloud cover was analysed with cloud masks from AVHRR/APOLLO and TERRA/MODIS cloud products. Availability of cloud-free images was determined from revisit frequency and the numbers of monthly images from Landsat ETM+, ASTER, Quickbird and SPOT satellite sensor series. The average number of cloud-free days at Risley Moss and Charter's Moss is five days per month with a minimum of one cloud-free day. The results show that satellite revisit periods and cloud cover are major determinants of satellite data availability and in this study it was also found that contrary to popular opinion, satellite overpass does not necessarily mean imaging opportunity and additional cloud-free images could be obtained when there are no satellite overpasses. The numbers of cloud-free images at a given site may be increased by combining data from different satellite sensors.
\end{abstract}

Keywords: cloud cover, cloud mask, satellite image, satellite revisit.

\section{Introduction}

Cloud cover information is vital in optical remote sensing because it determines the availability of data sets for many operational applications and may be used to determine whether a satellite overpass has an unobstructed field-of-view (FOV) of a specific pixel in a satellite image (Ackerman et al. 1998). The impact of cloud cover has been recognized for many years as an important source of error in the retrieval of many surface parameters from optical remote sensing (Cihlar et al. 1997). Clouds obstruct viewing at all solar wavelengths and even the part of the surface that is not directly underneath a cloud is often affected by reflections from cloud edges resulting in distortion of the actual reflectivity from the surface, while cloud shadows reduce surface illumination (VantHull et al. 2007).

Efforts made in reducing the effects of cloud cover on satellite data use compositing of selected cloud-free images in collocated pixels that are geometrically registered with the maximum Normalized Difference Vegetation Index (NDVI), or by compositing temporally overlapping satellites images of different overpass dates (Cihlar et al. 1997; Roy 2000). This method is suitable for high temporal resolution imagery, like TERRA/MODIS, but it reduces the available data so that short-term surface dynamics may be undetected; clouds may still be a major source of residual contamination in such composites. The selection of only cloud-free images may not meet the required numbers of multi-date sample images needed for atmospheric correction, radiometric normalization or bidirectional models (Schaaf et al. 2002). However, cloud cover is a limitation for the application of optical sensors in many geographical regions, especially when related to data from satellites with longer revisit periods. For example, in cloudy regions like the UK, the repeat coverage of the Landsat 7 ETM+ of 16 days is not likely to provide adequate data for the assessment of environmental dynamics that require temporally consistent images at different dates. The daily revisit capabilities of coarse/medium resolution satellite systems, such as NOAA-AVHRR, or TERRA/AQUA-MODIS, may be limited by their spatial resolution resulting in mixed pixels which can cause inconsistent calculation of the NDVI values because compositing daily images over a tenday or bi-weekly time period is likely to include cloudcontaminated pixels, while compositing the NDVI over longer compositing periods loses the advantage of high temporal resolution (Cihlar 1996; Fensholt et al. 2007; Luo et al. 2008).

To date, the accurate prediction of global distribution of cloud cover both in space and time has been problematic. The understanding of spatial and temporal variability of clouds needs to be improved by indicating, with a known level of confidence, whether a satellite has an unobstructed field-of-view (FOV) for a particular pixel location on the Earth's surface. The possibility 
of predicting the quality and availability of satellite data, with a high level of confidence, for continuous monitoring and retrieval of cloud-free pixels, at both temporal and spatial scales can be provided by the use of satellite cloud mask.

\section{Cloud masks}

Cloud masks from satellite data represent an important dataset in remote sensing applications because it is required to label pixels as either clear or cloudy before other geophysical products could be derived (Stubenrauch et al. 2002). However, its potential has not yet been extended to the extraction of cloud-free pixel/sub-pixel data for multi-temporal and multi-sensor remote sensing. Early estimates of cloud cover were based on surface observations of cloud distribution; this is subjective and lacks spatial information on cloud extent (Spinhirne et al. 1996; Young et al. 1998; Van Lammeren et al. 2000; Turner et al. 2003; Feister, Shields 2005). While cloud masks from satellite sensors have the advantage of being able to supplement surface observations and in-situ measurement, they can also distinguish the variability of clear and cloudy pixels simultaneously at appropriate spatial and temporal scales (Schreiner et al. 1993; Town et al. 2007).

Cloud masks are relatively simple ways to detect clear/cloudy pixels that meet different challenges depending on the satellite sensor, applications and environmental conditions. Cloud masks are derived by applying algorithms to the visible and the infrared channels of the satellite, based on the principle that cloud reflectance is high in the visible, and that clouds have lower temperatures than clear sky and land surface in the thermal infrared channels. Visible and infrared channel thresholds are used in combination with statistical classification and neural network procedures to enhance detection of clear/ cloudy pixels when the visible and infrared thresholds method fail, or are insensitive to cloud, especially over snow and ice (Rossow, Garder 1993; Logar et al. 1998; Krebs et al. 2007). Utilization of satellite imagery for the production of cloud masks has attracted a lot of attention with different types of satellite sensor leading to a variety of cloud detection schemes.

Noteworthy examples are the first cloud mask developed by the International Satellite Cloud Climatology Project (ISCCP: Rossow, Schiffer 1991), the Meteosat (Desbois et al. 1982; Derrien, Le Gléau 2005) and the Geostationary Operational Environmental Satellite cloud mask (GOES: Simpson, Gobat 1995; Jedlovec et al. 2008) for coarse sensors. Also included in the category of cloud mask algorithms developed for coarse resolution sensors are the varieties of cloud mask derived from the Advanced Very High Resolution Radiometer sensors series (AVHRR: Key, Barry 1989; Stowe et al. 1994, 1999; Franca, Cracknell 1995; Karlsson 2003; Kriebel et al. 2003) and the SPOT/VEGETATION sensor (Lissens et al. 2000). Medium resolution and multi-angle sensor cloud masks include cloud products derived from the MODerate Resolution Imaging Spectroradiometer (MODIS: Ackerman et al. 1998; Platnick et al. 2003; Zhang, Lohmann 2003; Zhang et al. 2003; Frey et al. 2008) and the MEdium Resolution Imaging Spectrometer (MERIS: Cornford, Lyaskovskiy 2004; Gomez-Chova et al. 2007). While the cloud masks from multi-angle sensors include the Along Track Scanning Radiometer series (ATSR/ AATSR: Shin et al. 1996; Cervino et al. 2000; Plummer 2005; Simpson et al. 2005), the Multi-angle Imaging SpectroRadiometer (MISR: Diner et al. 2000; Di Girolamo, Wilson 2003; Yang et al. 2007) and the Clouds and the Earth's Radiant Energy System (CERES) cloud mask (Wielicki et al. 1998). There are also cloud masks from high spatial resolution sensors like the Advanced Spaceborne Thermal Emission and Reflection Radiometer (ASTER: Logar et al. 1998), Landsat Automatic Cloud Cover Assessment (ACCA: Irish 2000), Landsat Cloud Detection using Shadow Matching (CDSM: Choi, Bindschadler 2004) and SPOT series (Liberti, Mezdari 2000). Cloud masks from microwave sensors include the TIROS Operational Vertical Sounder (TVOS: Wylie et al. 2005), the CloudSat Stephens et al. 2002; Im et al. 2005; Basilio et al. 2006; Sassen, Wang 2008), the Cloud-Aerosol Lidar with Orthogonal Polarization (Winker et al. 2007) and the POLarization and Directionality of the Earth's Reflectances (POLDER: Lier, Bach 2008).

The International Satellite Cloud Climatology Project (ISCCP) cloud mask scheme employs combination data sets from sensors on board geostationary satellite and polar orbiting satellites resulting in a large spatial resampling of radiance data to a $25 \mathrm{~km}$ grid. This limits the accuracy to which pixels can be collocated because the satellite pixel resolution used in the derivation of the cloud mask vary from 4 to $7 \mathrm{~km}$ (Rossow, Garder 1993; Rossow et al. 1993). Therefore, the radiance data cannot be representative of the actual radiance since radiance of the surface is not constant; the effects of artefact contamination from the footprints of geostationary observations have been reported (Norris 1999). Geostationary satellites like Meteosat and GOES imager/sounder cloud mask have very high temporal resolution of 15 and 30 minutes respectively but are limited by low and variable spatial resolution from the equator to the poles as a result of the curvature of the Earth (Menzel, Purdom 1994). The absence of a thermal band in the SPOT/ VEGETATION sensors raises the issue of compatibility with other sensors that have thermal bands (Lissens et al. 2000). The AVHRR Imager onboard NOAA was the first polar orbiting satellite instrument with both visible and infrared channels that are utilized in cloud mapping. The similarities among the AVHRR schemes are in their application of all the five spectral channels of the AVHRR instrument, however, they differ in terms of the spatial resolution, specification of thresholds/algorithms, combination of spectral bands and atmospheric corrections performed on each of the AVHRR cloud mask. The AVHRR Processing scheme Over cLouds, Land and Ocean (APOLLO) meets the requirement of this research in terms of temporal and spatial resolution, further discussed in the next section of this research.

The multi-angle imaging systems like MISR require nine separate cloud masks for each camera of the same scene, as a result of different view angles of the camera (Girolamo, Davies 1995). All cloud masks from ATSR 
instruments (ATSR-1/2/ and AATSR) are optimised for ocean use; therefore, it is necessary that improvements are made in the instruments before the scheme can be applied for land (Simpson et al. 2005). The revisit period of 9 days for MISR and 3 days for (ATSR-1/2/ and AATSR) make them unsuitable for this study. The TERRA/ CERES is designed specifically to provide cloud cover information by measuring clouds and the Earth's radiant energy budget however, the spatial resolution of 20 $\mathrm{km}$ also limit its usefulness for this study (Wielicki et al. 1996). The MODIS cloud mask uses 19 of the 36 spectral bands to maximize cloud detection in a combination with $250 \mathrm{~m}$ resolution bands and $1 \mathrm{~km}$ pixel resolution, while the MERIS cloud detection scheme is an automatic and stand-alone method that cannot handle static thresholds (Santer et al. 2000). The reliability of the results depends on the threshold selected on the bright flag definition. Also the 3 day revisit period of MERIS will not be appropriate for this study.

The high spatial resolution cloud mask from the Landsat Automatic Cloud Cover Assessment (ACCA) scheme gives good results over most of the land surfaces with the exception of ice sheets. The Landsat Cloud Detection using Shadow Matching (CDSM) scheme is an improvement on the Landsat ACCA algorithm, knowledge of the sun azimuth angle requirement limits the searching necessary to match possible clouds with possible shadows (Choi, Bindschadler 2004). The ASTER cloud mask is designed for Polar Regions and may not give good results over other regions; also the fuzzy classification, based on neural networks, requires very large central processing unit (CPU) memory for cloud mask derivation, making it unattractive for wide usage (Logar et al. 1998). The cloud mask from microwave imagers like TOVS, CloudSat, CALIPSO and POLDER can assist in mapping cloud cover in overcast conditions with vertical cloud structure assessments, but the poor spatial resolution of approximately 2.5 and $5 \mathrm{~km}$ is a major drawback (Wylie et al. 2005; Winker et al. 2007; Lier, Bach 2008; Sassen, Wang 2008).

This overview of cloud detection schemes shows that it is important to understand how cloud properties are observed by these different instruments taking into consideration the resolution properties, the type of detection schemes and scientific history of their applications. The improved, well established and extensively validated AVHRR/APOLLO scheme has served as the theoretical basis for other cloud detection algorithms including the TERRA/MODIS cloud mask (Gesell 1989; Kriebel 1990; Ackerman et al. 1998; Logar et al. 1998; Zavody et al. 2000). The TERRA/MODIS instrument has 36 bands of which 19 bands are used for cloud detection and make use of a very high temporal frequency interval of at least four scenes a day for AVHRR/APOLLO, and a daily coverage for TERRA/MODIS makes it possible to extend spectral classification with a detection of changes between images for the regions of interest. This improves the detection of clouds in instantaneous images which allows a more accurate mapping of cloud cover. Thus, the AVHRR/APOLLO scheme and TERRA/MODIS cloud mask are used in this study. This research is concentrated on daily cloud masks related to day-time acquisition of optical imagery, therefore, night cloud detection schemes are not mentioned in this research.

There are many factors that motivated this research. One key factor is to know the interaction between cloud cover and satellite revisit time in the North West of England by using two study sites, in order to assess the required revisit time for dynamic vegetation monitoring. This is because the knowledge of clear/cloudy pixels is critical to a number of applications in remote sensing in order to obtain accurate retrievals for atmospheric corrections, radiometric normalization, and bidirectional reflectance models. Other significant applications are the determination of the numbers of cloud-free images, to assist in searching of optical imagery archives, scheduling of high spatial resolution sensors and planning field validation exercises.

\section{Comparison of AVHRR and MODIS cloud mask algorithm}

The AVHRR on board the National Oceanic and Atmospheric Administration (NOAA) Polar Orbiting Environmental Satellites (POES) began operation with TIROS-N in 1978. Since then there have been 13 AVHRR sensors, the one on board of NOAA-13, launched in August 1993, failed but the five AVHRR sensors onboard of NOAA-11, NOAA-12, NOAA-15, NOAA-17 and NOAA-18 are currently operational (Kidwell 1995; Goodrum et al. 1999; Atkinson, Whyte 2003). The improved instrument version known as AVHRR/3, with 6 channels, started on NOAA15, launched in May 1998; and the latest AVHRR/3 is on board NOAA-18, launched in May 2005. The AVHRR/3 sensor acquires data in six spectral bands at $0.65 \mu \mathrm{m}$, $0.9 \mu \mathrm{m}, 1.6 \mu \mathrm{m}$ (day only), $3.7 \mu \mathrm{m}$ (night only), $11.3 \mu \mathrm{m}$ and $12.3 \mu \mathrm{m}$ in 10 bits. It is a sun-synchronous polarorbiting satellite using a whisk broom scanner and has a $1.1 \mathrm{~km}$ spatial resolution at nadir, swath of $2800 \mathrm{~km}$ and global temporal coverage of 4 times a day (Dash, Ignatov 2008). The APOLLO software is designed to process AVHRR High Resolution Picture Transmission (HRPT) data as well as Local Area Coverage (LAC) data both in full spatial resolution. Those pixels for which the solar elevation is more than $5^{\circ}$ above the horizon are processed by means of the daytime algorithms (http://www.wdc.dlr. de/apollo/). These methods of cloud detection are based on thresholds obtained from the two AVHRR channels of surface reflectance: (channels 1 and 2) and three thermal channels (channels 3, 4 and 5) as well as systematic mathematical expressions applied to the pixels to determine whether a pixel is cloud contaminated (cloudy/ partially cloudy), cloud-free, or snow/ice-contaminated. These results are combined in a cloud mask which can afterwards be cleared of cloud-free snow pixels using the $1.6 \mu \mathrm{m}$ channel. APOLLO is the first algorithm to make use of all five spectral channels of AVHRR (Kriebel et al. 2003), during daytime and to discretize all AVHRR data into four different groups called cloud-free, fully cloudy, partially cloudy, and snow/ice, before classification to eleven classes or twelve classes if there is sun glint.

The Moderate Resolution Imaging Spectroradiometer (MODIS) was launched on the NASA Earth Observing 
System (EOS) Terra platform in 1999 in a sun synchronous polar-orbit with a total of 36 spectral bands ranging from visible to infra-red $(0.415-14.235 \mu \mathrm{m})$ wavelengths using 12 bits. It is a whisk broom imaging radiometer employing multiple in-track detectors and cross-track scan mirror and collection optics with spatial resolutions at nadir of $250 \mathrm{~m}, 500 \mathrm{~m}$ and $1000 \mathrm{~m}$ and temporal resolution of 1 to 2 days with a swath width of $2330 \mathrm{~km}$ (Ackerman et al. 1998). The TERRA/MODIS cloud mask is derived by applying algorithms to 19 bands $(1,2,4,5$, $6,7,17,18,19,20,22,26,27,28,29,31,32,33$, and 35) with 14 tests (Platnick et al. 2003; Frey et al. 2008). The TERRA/MODIS cloud mask algorithm identifies clouds according to surface type and solar illumination, including land, water, snow/ice, desert, and coast for both day and night. Once a pixel has been assigned to an algorithm path, a series of threshold tests is performed to detect the presence of clouds in the instrument field of view, in addition, the four level masks derived, is converted to a binary mask. Each cloud detection test returns a confidence level that the pixel is clear ranging in value from 1 (high) to 0 (low). The product provides 48 bits of output per $1 \mathrm{~km}$ pixel that includes information on sets of multispectral test results, the processing path, and ancillary information such as a land/ocean tag. The first two bits are the focus of the analysis here, provide information in four categories: confident clear, probably clear, uncertain/probably cloudy, and cloudy.

Similarities in both AVHRR/APOLLO and TERRA/MODIS cloud detection schemes are in the application of reflectance and infrared thresholds using pixel level spectral tests. Even though the theoretical basis of MODIS cloud mask algorithm was derived from APOLLO scheme, they differ in spatial resolution, specification of thresholds, combination of spectral bands and atmospheric corrections (Kriebel et al. 2003; Ackerman et al. 2008). Among the differences are the numbers of tests used, AVHRR/APOLLO uses five tests while TERRA/MODIS cloud mask uses fourteen tests and the spectral bands used, AVHRR/APOLLO uses five bands while TERRA/MODIS uses nineteen bands. The spatial resolutions of the instrument are also different; AVHRR/ APOLLO is $1.1 \mathrm{~km}$ while MODIS is $1 \mathrm{~km}$ with collocated $250 \mathrm{~m}$ resolution.

There are also differences in the availability of specific wavebands which on TERRA/MODIS greatly improve cloud detection of thin cirrus cloud and water vapour in the wavebands at 1.38 and $7.7 \mu \mathrm{m}$, which are absent in AVHRR/APOLLO (Kriebel et al. 2003; Platnick et al. 2003). The bandwidths and spectral response associated with the red and NIR band used in deriving cloud mask differ for the TERRA/MODIS and AVHRR sensors. The TERRA/MODIS red (nominally 0.620 to $0.670 \mu \mathrm{m})$ and NIR $(0.841$ to $0.876 \mu \mathrm{m})$ bands are much narrower than the AVHRR/APOLLO red (0.585 to 0.680 $\mu \mathrm{m})$ and NIR $(0.730$ to $0.980 \mu \mathrm{m})$ bands. The test applied in the brightness temperature difference test are not the same; for APOLLO the test is based on the split window technique in the infrared spectral range in band 4 and $5(10.3-11.3 \mu \mathrm{m}$ and $11.5-12.5 \mu \mathrm{m})$ whilst a tri-spectral technique of split window is applied in the TERRA/ MODIS cloud detection algorithm (Frey et al. 2008; Frey
2003; Strabala 2005). TERRA/MODIS detects aerosol, shadow and uses a Normalized Difference Snow Index (NDSI) in the cloud mask algorithm which it is not included in the AVHRR/APOLLO scheme. In addition, the classification of the images into categories are different; AVHRR/APOLLO is classified into eleven or twelve classes depending whether there is sun glint, while the TERRA/MODIS cloud mask is classified into four.

The aim of this paper therefore, is to examine the spatial and temporal variation of cloud cover in the UK in relation to satellite revisit times. In order to accomplish these goals, cloud masks from AVHRR/APOLLO scheme and TERRA/MODIS cloud products were used to extract cloud cover information. This paper includes a comparison of AVHRR/APOLLO and TERRA/MODIS cloud mask data, outlines the experimental design, analysis of spatial variations in cloud cover frequency in the UK and assesses this in relation to satellite revisit schedules for the test sites.

\section{Determination of satellite revisit schedules for the test sites}

Satellite revisit period is the time interval that a satellite sensor images the same location on the Earth surface (Johnson et al. 1994). The knowledge of revisit period of the satellite over a given location can be used to determine the amount of satellite data that is available for any application and the time interval between revisits is critical in the monitoring of frequent and rapidly changing environments, such as, agricultural practices and natural disaster mitigation, also important in accurate map revision and change detection which requires multi-temporal analysis (Durpaire et al. 1995). Revisit period is determined by many factors among them are orbital cycle of satellites, swath width, type of sensors/camera, the orbit of the satellite, latitude, purpose of satellite sensors, areas of overpass, constellation of satellite sensors and environmental conditions (Arvidson et al. 2001; Aguttes et al. 2004).

Satellite overpass days were determined for Risley Moss and Charter's Moss using web-based overpass predictors for Landsat ETM+ and ASTER. Catalogue services for available data sets were accessed from the provider's websites to determine overpass days for Quickbird and SPOT series (2, 4, and 5), also for confirmation of overpass days for Landsat ETM+ and ASTER. The revisit frequency of the satellite sensors used in this research ranged from a minimum of every 7 days for Quickbird to a maximum of every 26 days for the SPOT series while Landsat ETM+ and ASTER sensors have a revisit of every 16 days. For sensors with off-nadir viewing and programmable viewing angle capabilities like Quickbird and SPOT series, the revisits dates varies depending on the latitude and proximity of area of interest, but for UK for example, Quickbird is every 7 days and SPOT series every 5 days due to programming of the camera. Although other sensors exist, they were not considered because of difficulties in obtaining accurate overpass dates. Therefore, the analysis of the relationship between satellite revisit and cloud cover will be restricted to the above mentioned sensors during overpass dates and the dates that data are available. 


\section{Experimental design}

Cloud data sets used in this study were downloaded for AVHRR/APOLLO and TERRA/MODIS cloud masks from the website archive of the German Aerospace Centre (http://wdc.dlr.de:8082/apollo/) and the National Aeronautics and Space Administration (http:// ladsweb.nascom.nasa.gov/data/ftp_site.html), respectively, for the period from January 1st to December 31 st in the year 2005. Since the daily overpass times of the AVHRR/APOLLO and TERRA/MODIS vary daily, only daytime images covering the $\mathrm{UK}$ in a time window between 09:30 and 12:30 Universal Time (UT) were selected. The images from AVHRR/APOLLO were geometrically corrected to the UTM WGS84 coordinate system by selecting 30 evenly distributed ground control points (GCP) derived from Ordnance Survey map in the British national grid reference system which were then converted to UTM coordinates by coordinate converter. The selected points were used to correct the "best" AVHRR/APOLLO image, which was of 27 October 2005, using the second order polynomial and the image was resampled to $1.1 \mathrm{~km}$ pixel size. Thereafter, the AVHRR/APOLLO image of 27 October 2005 was used to correct other images. The TERRA/MODIS data was extracted and uncompressed using the HDF View tool. A Matlab programme supplied by the MODIS support team was used to read TERRA/MODIS cloud mask data. The TERRA/MODIS data was reprojected with the MODIS Reprojection Tool Swath (MRTSwath) and resampled to $1 \mathrm{~km}$ pixels in the UTM WGS84 coordinate System. Erdas imagine was used for the image processing and modelling. An area of interest image covering the UK land surface was extracted from both sensors using a shapefile mask representing the UK boundaries, the Northern Ireland was excluded for convenience because it uses the Irish grid reference system which is different from the UK British National Grid reference system, this would have an effect on the geolocation accuracy of the satellite data westwards. There were 130 images missing for AVHRR/APOLLO while for TERRA/MODIS 8 images were missing. The reasons for AVHRR/APOLLO missing images are that some days were too cloudy, making it impossible for the sensor to detect enough coastline boundaries for geo-referencing, instrument failures leading to one or even a few pixels deviation and data are sometimes not acquired during weekends, public holidays or during the eastern overpass of AVHRR sensor (http://wdc.dlr.de:8082/ apollo/). While the missing data for TERRA/MODIS are as a result of artifacts occurring in the detectors due to the scanning edge failure in retrieving images and insufficient interpolation to the $1 \mathrm{~km}$ scales (Haran et al. 2002; Platnick et al. 2003). The cloud mask algorithm is not determined or not executed when there is missing data or invalid radiance data, geo-location data and artifacts caused by sun glint (Ackerman et al. 1998; Platnick et al. 2003; Strabala 2005). The number of AVHRR/APOLLO daily images used was 235 (43 partial coverage of the UK) and in case of TERRA/MODIS, 357 daily images were used (115 partial coverage of the
UK). All the images were reclassified and recoded into binary images reducing the eleven or twelve classes of AVHRR/APOLLO and four classes of TERRA/MODIS into two classes of 0 and 1 . A value of 0 was allocated to a pixel if it was cloudy or no data was collected and a value of 1 if the pixel was cloud-free. The determination of cloud frequency took into account the numbers of days that the algorithm was executed for each pixel.

Monthly and annual images of both AVHRR/APOLLO and TERRA/MODIS were processed from January to December 2005 to produce two stacks of binary files. The pixel values of the images within the first stack indicate a probability of cloudy areas (0) or a clear sky (1); while the pixel values of the images within the second stack indicate not executed (0) and executed (1) cloud mask algorithm. Examples of monthly and annual output of the Erdas Imagine Modeler tool, showing cloud cover probability in the UK before it classified into different categories with colours.

\section{Comparison of AVHRR and MODIS cloud mask data}

Annual and monthly images were classified with ArcGIS software for visual analysis and spatio-temporal comparison of AVHRR/APOLLO and TERRA/MODIS data. Stacked monthly images were classed into six categories ranging from $0-1.1 \%$ to $80.1-100 \%$ while one year stacked images were categorised into ten classes of $5 \%$, from $0-5 \%$ to $>45 \%$ (Figs. $1,2,3$ and 4 ). Monthly images were classified differently from the annual images because of different ranges of the data and in order to accommodate wider range of the monthly data.

March is the cloudiest month for the two images. There was increase of cloud-free pixels in May while June is the highest cloud-free month with the highest cloudfree frequency classes mainly in 40.1-60\% for AVHRR/ APOLLO; while for TERRA/MODIS data the classes are mainly 20.1-40\% (Figs. 1 and 2).

Monthly means for stacked images were extracted into bins of six classes of cloud-free pixels ranging from $0-1.0 \%$ to $80.1-100 \%$. For conveniences and in order to accommodate all data range from 0 to $100 \%$, the first class was from $0-1.0 \%$ and after, the other classes were in intervals of $20 \%$. The class from $0-1.0 \%$ also included no data (Fig. 2). Visual examination of the histograms shows that for both AVHRR/APOLLO and TERRA/MODIS were represented in 3 classes of $0-1.0 \%$, $1.1-20 \%$ and $20.1-40 \%$ in all of the months except for the month of March in TERRA/MODIS data, when the class of $20.1-40 \%$ was absent while AVHRR/APOLLO was represented in all classes $(0-1.0 \%$ to $80.1-100 \%)$, though the frequency of cloud-free pixels decreases as percentages of cloud-free pixels increases. The maximum class of monthly mean of cloud-free pixels varies for both AVHRR/APOLLO and TERRA/MODIS; AVHRR/ APOLLO has the maximum value of $100 \%$ in 11 months with the exception of January with $80 \%$ as the month with the lowest cloud-free pixels; while TERRA/MODIS has August as the maximum with $70 \%$ and the lowest in March with $43 \%$. 


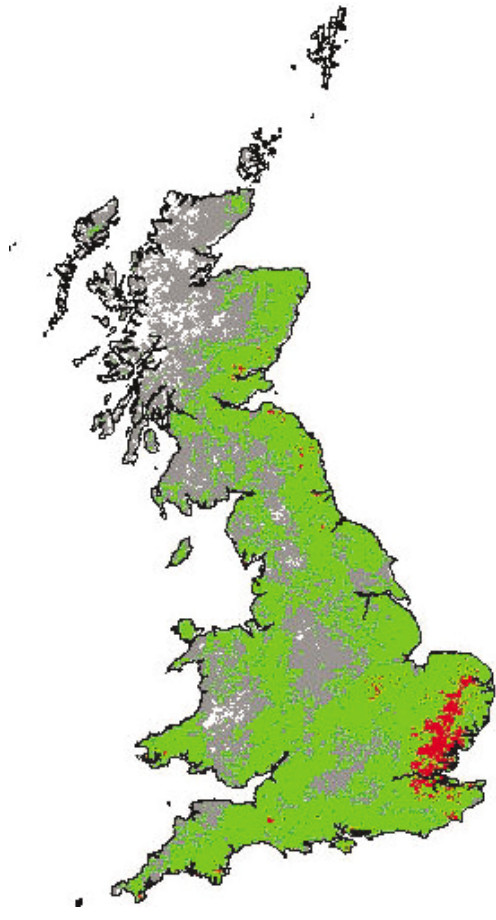

a) AVHRR/APOLLO January

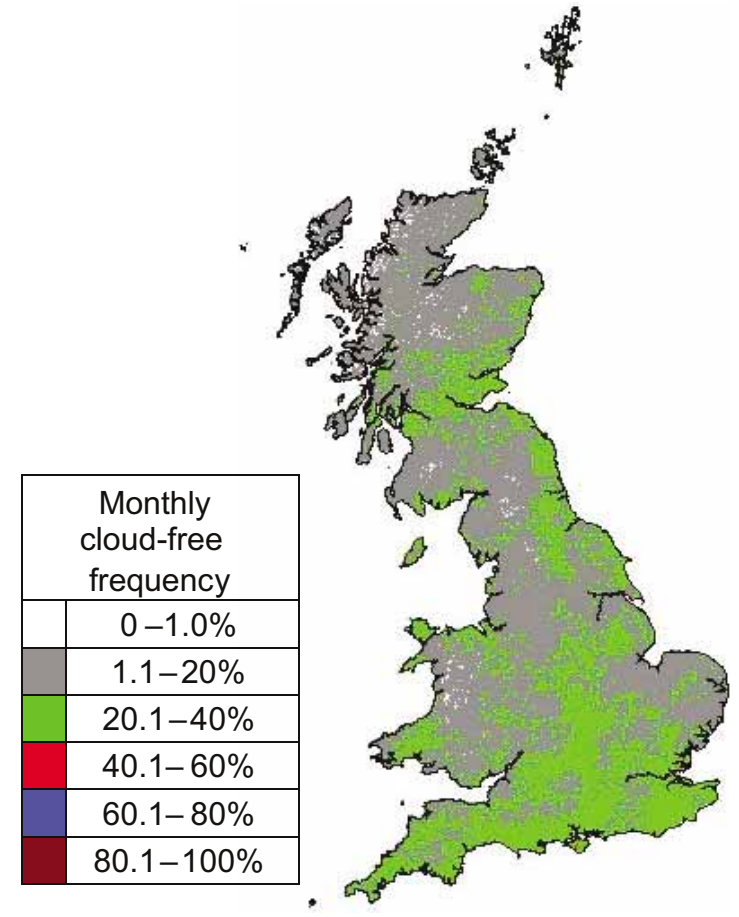

b) TERRA/MODIS January

Fig. 1. Classification of monthly cloud-free pixels in the UK

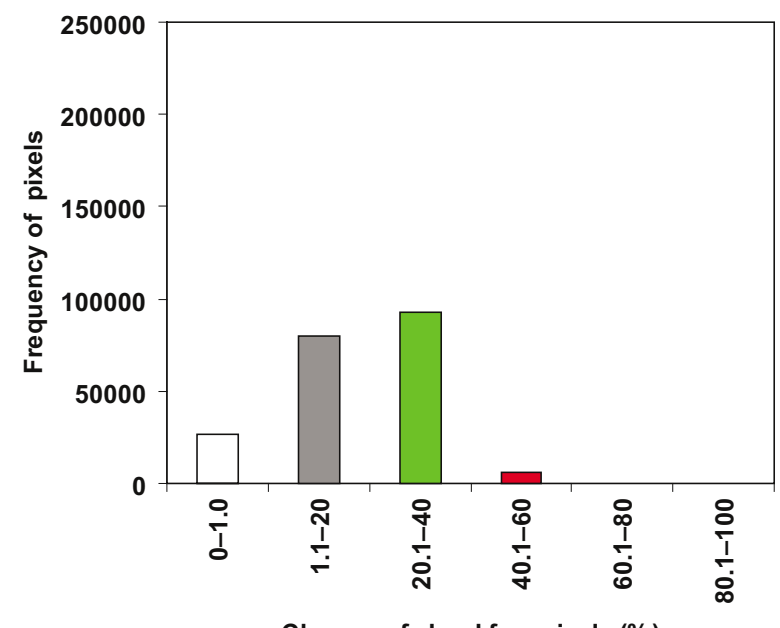

a) AVHRR/APOLLO January

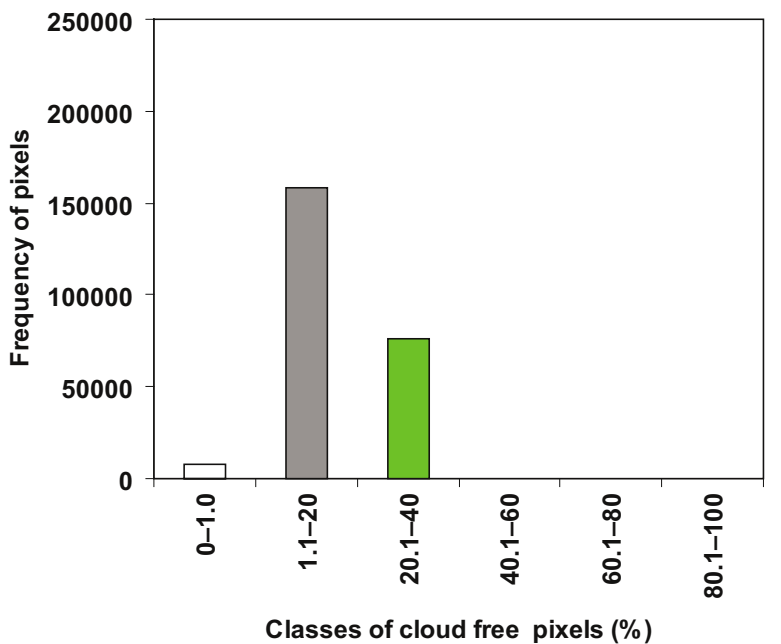

b) TERRA/MODIS January

Fig. 2. Histogram of monthly cloud-free pixels in the UK

Monthly mean ranges from the lowest value of $3.31 \%$ in March to the highest value of $9.54 \%$ in June for AVHRR/APOLLO while for TERRA/MODIS the lowest mean was $3.87 \%$ in March to the highest mean value of $9.86 \%$ in November. The month of March has the lowest standard deviation for both AVHRR/APOLLO and TERRA/MODIS with values of $7.04 \%$ and $7.59 \%$ respectively. The minimum monthly percentage of cloud-free pixel was 0 for both AVHRR/APOLLO and TERRA/ MODIS.

The result for the whole year shows a minimum of $0 \%$ cloud-free for a single pixel for both AVHRR/
APOLLO and TERRA/MODIS while the maximum was $49 \%$ and $46 \%$, respectively. The standard deviation for AVHRR/APOLLO was $12.44 \%$ while it was $12.92 \%$ for TERRA/MODIS. The mean percentage of cloud-free days for the whole UK was 7.68\% for AVHRR/APOLLO and $8.12 \%$ for TERRA/MODIS cloud data.

Histogram analysis shows that the percentage interval of $25.1-30 \%$ has the highest frequency. This is due to the inclusion of the ocean but the majority of cloud-free pixels in the mainland are within the category of 25.1$30 \%$ followed by $30.1-35 \%$ for both images and the lowest frequency was $45.1 \%$ and above (Fig. 4). 


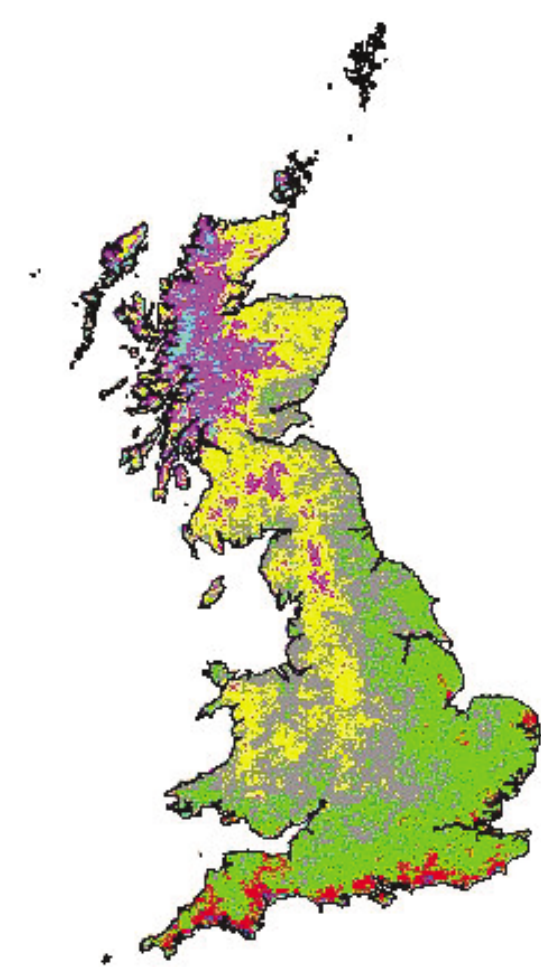

a) AVHRR/APOLLO One year (2005)

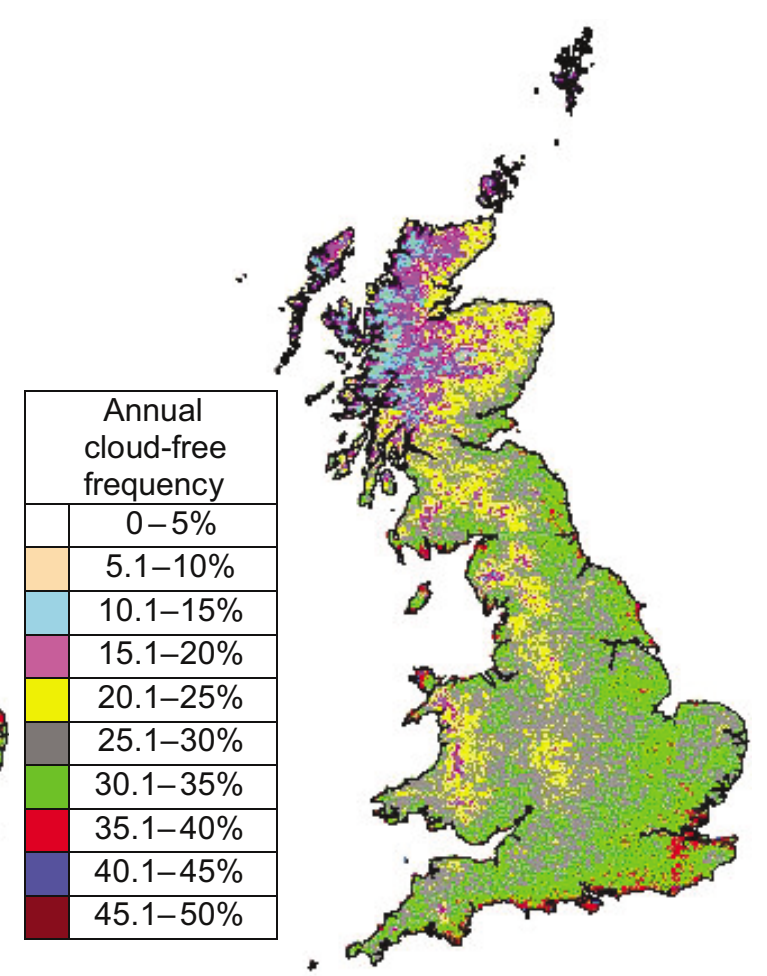

b) TERRA/MODIS One year (2005)

Fig. 3. Classification of (a) AVHRR/APOLLO and (b) TERRA/MODIS one year image of cloud-free areas in the UK

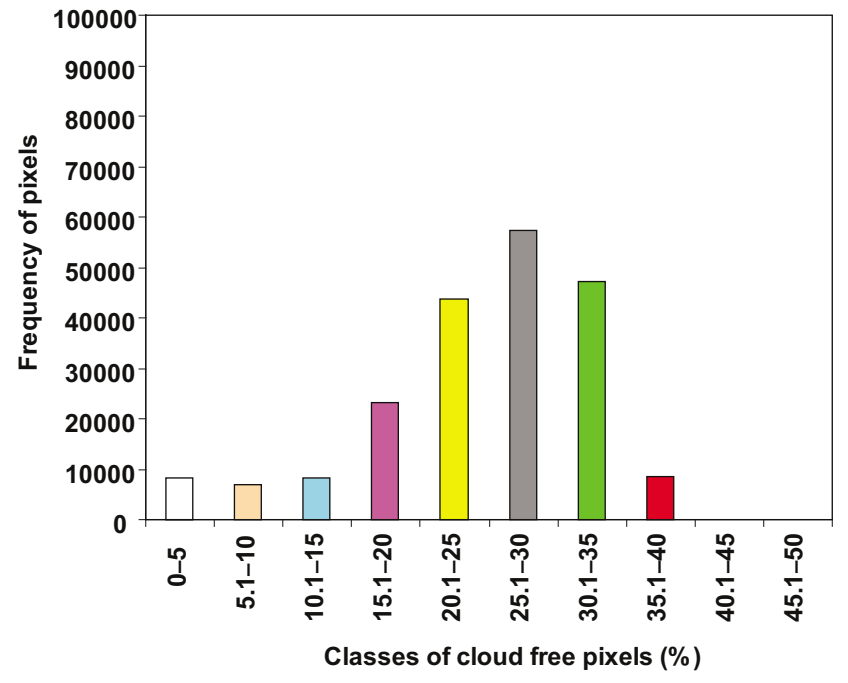

a) One year AVHRR/APOLLO (2005)

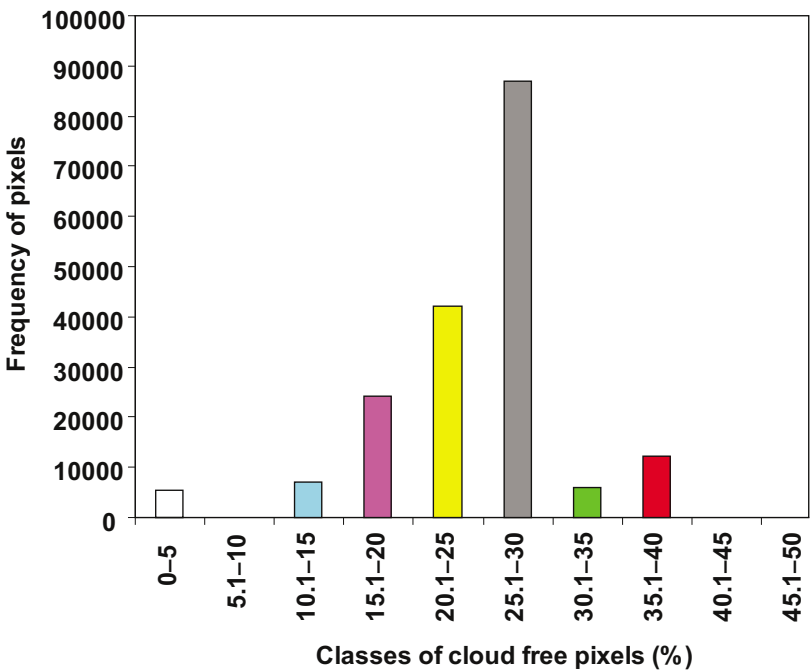

b) One year TERRA/MODIS (2005)

Fig. 4. One year histogram of (a) AVHRR/APOLLO and (b) TERRA/MODIS image classes of cloud-free areas in the UK

\section{Spatial and temporal variations in cloud cover frequency in the UK using MODIS cloud mask}

TERRA/MODIS cloud mask data have a number of advantages over AVHRR/APOLLO cloud data in terms of spectral resolution, number of channels and spatial resolution used in deriving cloud mask. For the year 2005, the numbers of daily AVHRR/APOLLO datasets available are few; $65.28 \%$ for the whole year when compared with TERRA/MODIS cloud mask datasets available for the same period that was $97.81 \%$ based on data avail- ability, AVHRR/APOLLO datasets are not likely to be reliable as TERRA/MODIS with more datasets, henceforth AVHRR/APOLLO data will not be used in the next section analysis. Spatial and temporal variations of cloud cover frequency in the UK were analysed from January to December 2005 using the TERRA/MODIS cloud mask. Spatial variations were examined by extracting mean annual percentages and standard deviation of cloud-free pixels over widely distributed specific locations in the UK. 


\subsection{Spatial variations over the whole year}

Twenty four locations were selected from north to south for this analysis. Stornoway has the lowest number of cloud-free pixels which was $14.75 \%$ and Land's End has the highest with $37.25 \%$. The standard deviation was generally higher for most locations in the north than in the south. Birmingham has the lowest standard deviation of $5.82 \%$ and Brighton has the highest standard deviation of $11.27 \%$ (Fig. 5).

\subsection{Temporal variations in cloud cover over the UK}

Temporal variations of the frequency of cloud-free pixels in the UK in the year 2005 were derived from modelled monthly images. The lowest mean percentage of cloudfree pixels was in March with value of $3.87 \%$ and the highest - in November with $9.86 \%$. There was fluctuation in the numbers of cloud-free pixels throughout the year with standard deviation range from $7.04 \%$ as the minimum in March to the maximum of $16.26 \%$ in November (Fig. 6).

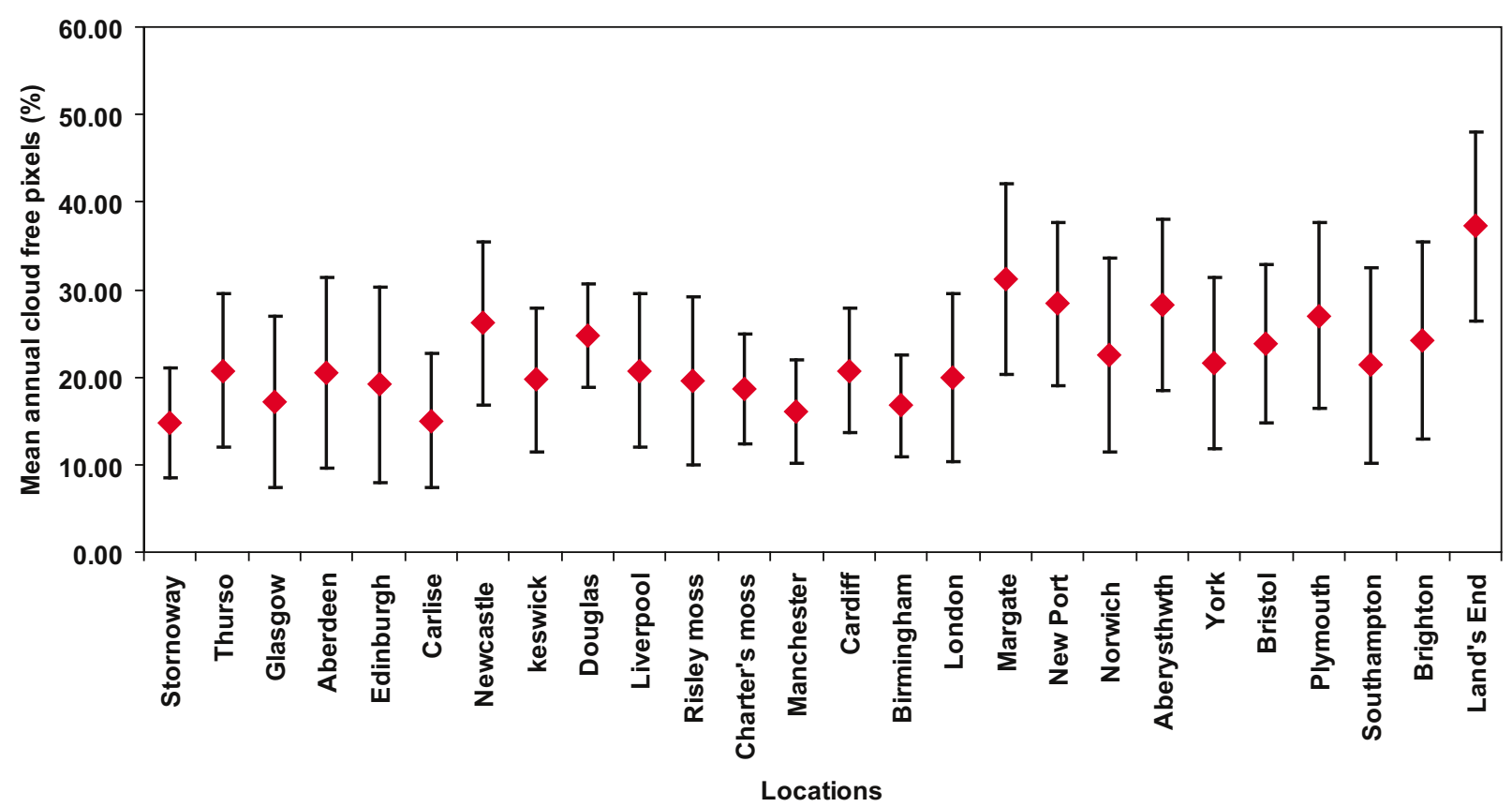

Fig. 5. One year clear pixels and standard deviation of selected locations in the UK

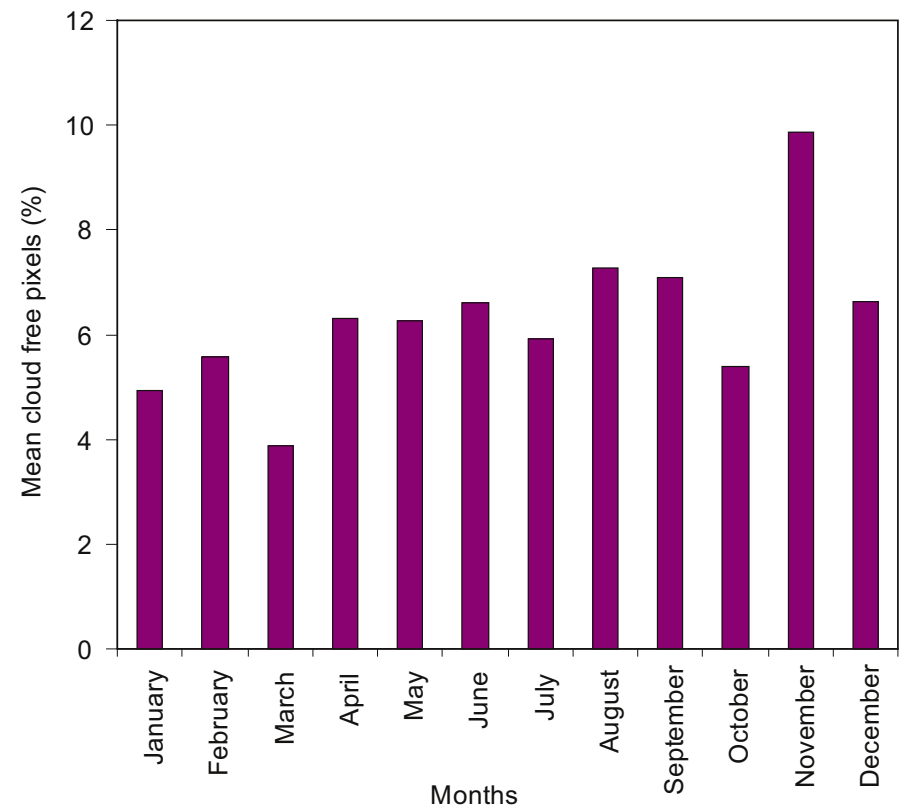

Fig. 6. Mean monthly variations of cloud-free pixels in the UK 
The analysis of monthly variations in cloud cover at the study sites is discussed in the next section.

\section{Cloud cover over the study sites}

Variations in the cloud-free pixels statistics for the study sites were examined. The mean for Risley Moss was $19.58 \%$ while Charter's Moss was $18.67 \%$. The standard deviation at Risley Moss was $9.61 \%$ while the value at Charter's Moss was $6.24 \%$. The minimum monthly mean percentage of cloud-free pixels for Risley Moss was 3\% in April and the maximum of $34 \%$ in September while for Charter's Moss the minimum was $13 \%$ in March and maximum was $32 \%$ in November. From the results of both spatial and temporal variation, Risley Moss is cloudier than Charter's Moss even though Risley Moss had the highest cloud-free percentages in the month of November, the cloud-free pixels were not spread over time, also Risley Moss has the lowest cloud-free percentage in April (3\%) (Fig. 7).

\subsection{Modelling cloud cover and satellite revisit period}

The acquisition of cloud-free imagery for a given location depends on the frequency of cloud-free conditions and the frequency of satellite image data collection for that location. In this section a theoretical cloud-free image frequency (CFIF) is derived from:

$$
\text { CFIF days }=\frac{365}{R} \times \frac{C F F}{100} .
$$

Where $R$ is the satellite revisit period in days, and $\mathrm{CFF}$ is the annual cloud-free frequency for a given location from the MODIS cloud mask analysis. This theoretical approach was used to model cloud cover and cloud-free satellite image availability in the study sites using satellite revisit periods of Quickbird 7 days, Landsat ETM+ 16 days, ASTER 16 days and SPOT series 26 days. The results show that Risley Moss has the highest numbers of cloud-free images with 29 cloud-free images while Charter's Moss has 28 cloud-free images.

The previous analysis allows determination of the theoretical numbers of cloud-free images for a given location while in the next section practical approach was used to determine the actual numbers of cloud-free days and actual numbers of images available in 2005. The practical approach involves searching the archive or contacting the satellite data provider and extracting daily cloud cover conditions of a chosen location to using daily cloud mask. This becomes necessary because satellite data providers do not always collect data when the satellite passes over a given location. For example, the overpass time of Landsat ETM+ is every 16 days but the period of overpass days does not necessarily mean imaging opportunities because of the Landsat ETM+ Long Term Acquisition Plan (LTAP). LTAP is an automatic scheduler that applies a set of algorithms to schedules image acquisitions in accordance with favourable environmental conditions including cloud cover (Arvidson et al. 2001) meaning that Landsat ETM+ does not acquire data every 16 days at a particular location.

\subsection{Cloud-free image frequency for the study sites}

A realistic practical approach was used to investigate the frequency of cloud-free days at the study sites. Frequencies of cloud-free days were determined by extraction of the central pixel values from daily images for Risley Moss and Charter's Moss, at Risley Moss the lowest number of cloud-free days was January with 1 day and the highest was 9 days in November. At Charter's Moss the lowest was 2 days in March, April and October. November has the highest numbers of cloud-free days with 9 days (Fig. 8).

The total numbers of images available for the year 2005 were determined for each month and during overpass days for the two study sites. SPOT satellite sensors series were not used in this analysis because of the unreliability of the revisit periods and most images available from SPOT satellite sensors series are off-nadir images which will not serve the purpose of this research. In the two study sites, the total numbers of images available were the same, which was 34 . However, the numbers of cloud-free images were different: in Risley Moss there were 9 images that were cloud-free while for Charter's Moss it was only 5 images that were cloud-free (Figs. 9 and 10).

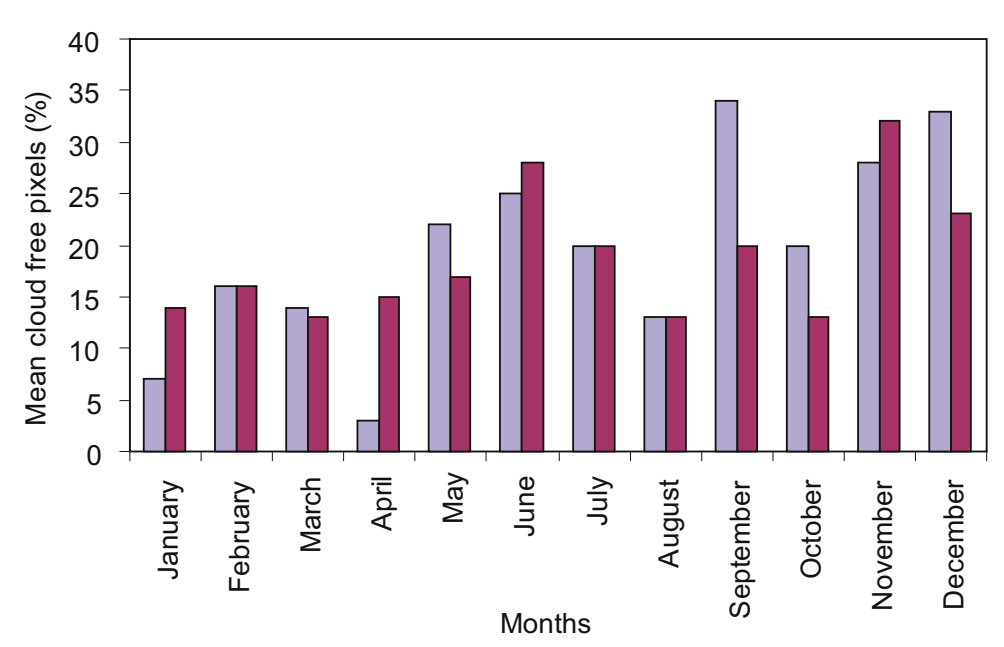

Fig. 7. Monthly variations of mean cloud-free pixels in the study sites 


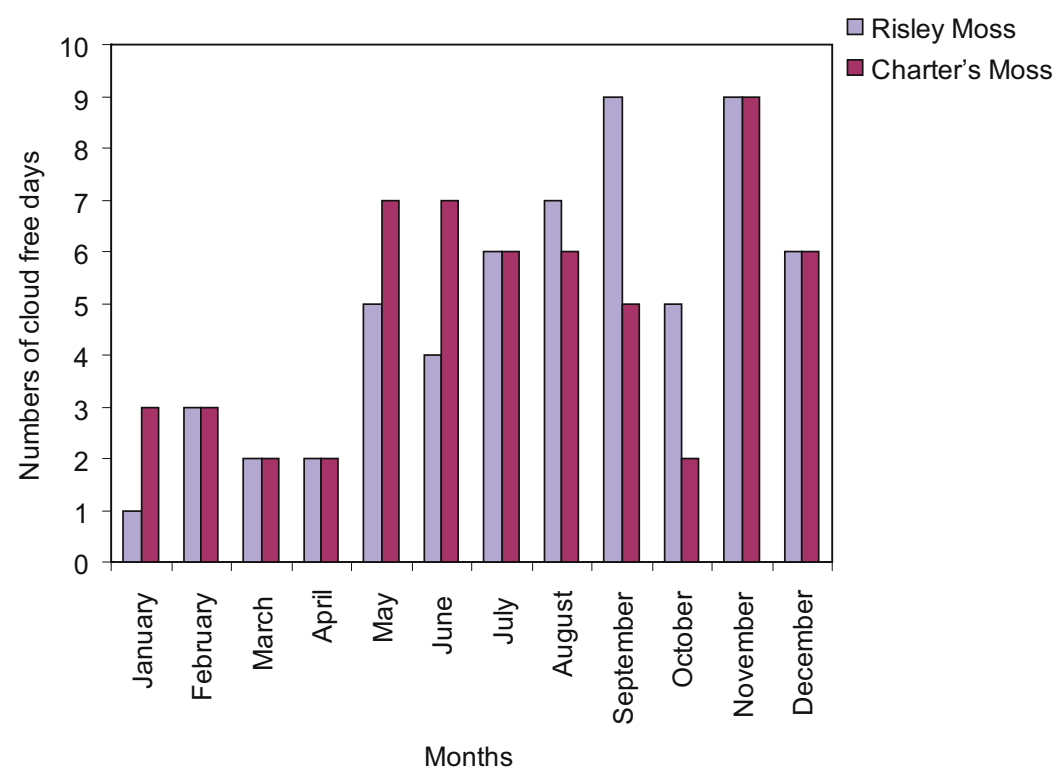

Fig. 8. Frequency of cloud-free days in Risley Moss and Charter's Moss

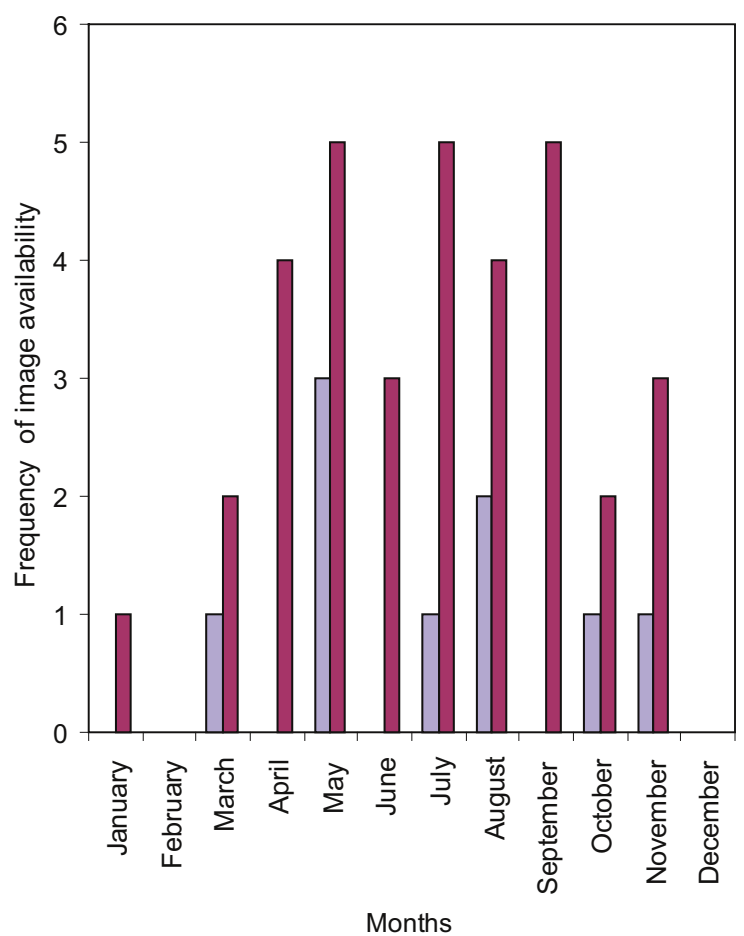

$\square$ Cloud free

$\square$ Total numbers

of images

Fig. 9. Frequency of numbers of total and cloud-free image availability in Risley Moss

Landsat ETM+ has the highest numbers of available images with 25 images when compared with ASTER with 7 images despite the fact that both Landsat ETM+ and ASTER have the same dates and revisit period of every 16 days also Landsat ETM+ has more images in comparison to the Quickbird with every 7 day revisit days. Quickbird satellite sensor had 2 images which was the lowest data acquisition for all the satellite sensors used in this analysis. Over the year, the availability of images varies from months to months. At Risley Moss, there were no images in February and December; also, no cloud-free images in January, February, April, June and September and December. The months with the highest numbers of images were May, July and September with 5 images each; however, September has no cloud-free images while July has only 1 cloud-free image and May has the highest with 3 cloud-free images. At Charter's Moss, there was no image in February and December; while the highest numbers of cloud-free images was 1 in May, July, August, October and November in other months of the year there were no images. 


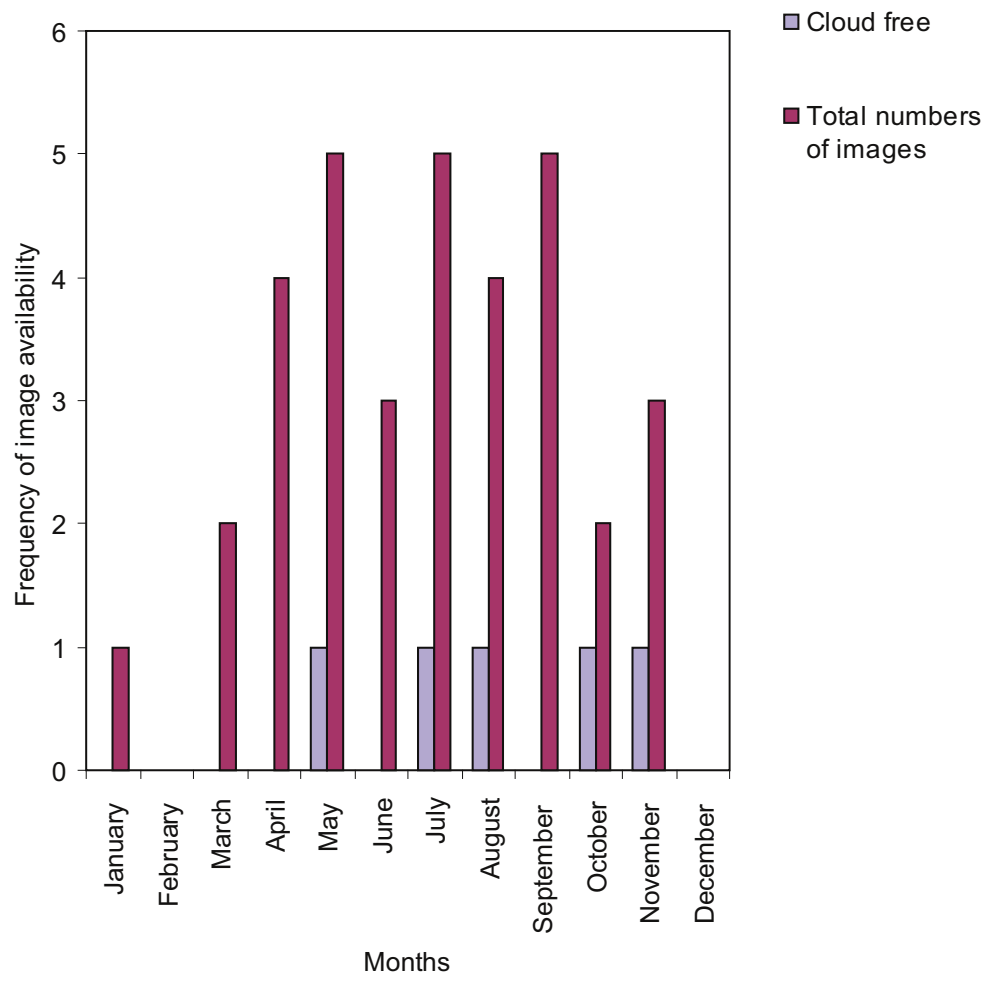

Fig. 10. Frequency of numbers of total and cloud-free image availability in Charter's Moss

\section{Discussion and conclusions}

Cloud cover probability was modelled over the UK and in particular for the two study sites in the North West of England using cloud masks from the AVHRR/APOLLO and TERRA/MODIS cloud products. The objective of using the cloud masks was to determine the availability of cloud-free images and to look at the possibilities of combining datasets from different satellite sensors in order to investigate the feasibility of multi-temporal remote sensing application, which required images acquired several times per month.

The first step involved comparing the qualities of cloud mask products from different satellite sensors and eventually the cloud masks derived from AVHRR and MODIS data sets were chosen. In the final analysis, the TERRA/MODIS cloud mask data were used because of its higher availability in 2005, with 357 images; while the AVHRR/APOLLO cloud mask had 235 images, making the TERRA/MODIS more reliable in terms of availability over the year in comparison to the AVHRR/APOLLO cloud mask. Other advantages of TERRA/MODIS over AVHRR/APOLLO datasets and the reasons why TERRA/MODIS cloud masks was chosen were discussed earlier in this paper.

Cloud mask can clearly be a useful tool in the assessment of cloud cover at both spatial and temporal scales. The two cloud masks used in this study are from different satellite sensors. The analysis shows that the results were not similar; this is due to the differences in the algorithms applied for deriving the cloud masks. It would be useful to carry out further research to asses through observation the information content of the cloud mask products. Issue of validation, geometric correction and spatial correlation of cloud mask products also warrant further investigation as these are not considered in this study. There is a need for a unified cloud masks classifications such as in the ground-based measurements of cloud cover whereby a unified octas systems is used even though different instruments are used to derive ground data of cloud cover. The TERRA/MODIS cloud mask data is more available and therefore reliable than the AVHRR/APOLLO. It is noted that the observed cloud condition from 2005 may not be typical and analysis of other time-periods will be useful.

Cloud cover frequency in the UK leads to a requirement for higher temporal resolution remote sensing data to monitor changes in vegetation phenology. This research shows that on the basis of satellite-derived cloud cover data at least one cloud-free image per month (and often more) may be acquired at both sites in the North West of England.

The results show that at Risley Moss, the average numbers of cloud-free days was 5 days with a minimum of 1 day in January and 9 days as the most in September. At Charter's Moss, the average number of cloud-free days was 5 days with the minimum of 2 days in the months of March, April and October; and 9 days as the highest in November. The implication of this result is that in a month, 1 cloud-free images can be acquired for each of the sites; meaning that for the whole year, 12 cloudfree images can be available for multi-temporal analysis. The total numbers of images available for Risley Moss was 34, of which 9 images were cloud-free; and in Charter's Moss, out 34 images, 5 images were cloud-free. This study fulfils the research aim to determine the numbers of cloud-free images that are available for the planning of field validation exercise. 
Satellite revisit periods and cloud cover are major determinants of satellite data availability and in this study it was found that contrary to popular opinion, satellite overpass does not necessarily mean imaging opportunity and image availability. For example, images of Landsat ETM+ were not available for the study sites until April; this was because of Landsat ETM+ long-term acquisition plan, which means that images are not necessarily acquired every 16 days (Arvidson et al. 2001). The Quickbird satellite has the highest revisit frequency but the lowest numbers of images available due to the commercial nature of its operation that does not allow image acquisition except on request. Also, there other factors that can determine imaging opportunity and image availability, among these are: orbital cycles, longitudinal/ latitudinal location, and mission of the provider. There is a need for a better definition and generally accepted meaning of satellite "revisit period", "temporal coverage", "temporal resolution"and "overpass" as these words do not necessarily mean an imaging opportunity at nadir. There is a need for a better definition and generally accepted meaning of satellite revisit period, temporal coverage and overpass as these words does not necessarily mean imaging opportunity at nadir.

\section{Acknowledgements}

The author wishes to thank his research supervisors Prof. F. M. Danson and Dr. R. P. Armitage for their advice and support throughout my $\mathrm{PhD}$ programme at the University of Salford in the UK.

\section{References}

Ackerman, S. A.; Strabala, K. I.; Menzel, W. P.; Frey, R. A.; Moeller, C. C.; Gumley, L. E. 1998. Discriminating clear sky from clouds with MODIS, Journal of Geophysical ResearchAtmospheres 103: 32141-32157.

http://dx.doi.org/10.1029/1998JD200032

Ackerman, S. A.; Holz, R. E.; Frey, R.; Eloranta, E. W.; Maddux, B. C.; Mcgill, M. 2008. Cloud detection with MODIS. Part II: validation, Journal of Atmospheric and Oceanic Technology 25: 1073-1086.

http://dx.doi.org/10.1175/2007JTECHA1053.1

Aguttes, J. P.; Fernandez, N.; Foliard, J. 2004. Potential of elliptic orbits for theatre observation, Acta Astronautica 55: 659-668. http://dx.doi.org/10.1016/j.actaastro.2004.05.040

Arvidson, T.; Gasch, J.; Goward, S. N. 2001. Landsat 7’s longterm acquisition plan - an innovative approach to building a global imagery archive, Remote Sensing of Environment 78: 13-26. http://dx.doi.org/10.1016/S0034-4257(01)00263-2

Atkinson, N.; Whyte, K. 2003. Further development of the ATOVS and AVHRR processing package (AAPP), including an initial assessment of EARS radiances, in Proceedings of the Thirteenth International TOVS Study Conference, 444-451.

Basilio, R.; Im, E.; Rokey, M.; Vane, D. 2006. A Spaceborne Microwave Radar System for Looking Inside Clouds SPIE. 63610D p.

Cervino, M.; Levizzani, V.; Serafini, C.; Bartoloni, A.; Mochi, M.; Colandrea, P.; Greco, B. 2000. Cloud fraction within GOME footprint using a refined cloud clearing algorithm, Advances in Space Research 25: 993-996.

http://dx.doi.org/10.1016/S0273-1177(99)00462-7
Choi, H.; Bindschadler, R. 2004. Cloud detection in Landsat imagery of ice sheets using shadow matching technique and automatic normalized difference snow index threshold value decision, Remote Sensing of Environment 91: 237-242. http://dx.doi.org/10.1016/j.rse.2004.03.007

Cihlar, J. 1996. Identification of contaminated pixels in AVHRR composite images for studies of land biosphere, Remote Sensing of Environment 56: 149-163. http://dx.doi.org/10.1016/0034-4257(95)00190-5

Cihlar, J.; Ly, H.; Li, Z. Q.; Chen, J.; Pokrant, H.; Huang, F. T. 1997. Multitemporal, multichannel AVHRR data sets for land biosphere studies - Artifacts and corrections, Remote Sensing of Environment 60: 35-57.

http://dx.doi.org/10.1016/S0034-4257(96)00137-X

Cornford, D.; Lyaskovskiy, A. 2004. MERIS cloud masks: exploration and visualisation of MERIS spectra, in European Space Agency, (Special Publication) ESA SP, 25-30.

Dash, P.; Ignatov, A. 2008. Validation of clear-sky radiances over oceans simulated with MODTRAN4. 2 and global NCEP GDAS fields against nighttime NOAA15-18 and MetOp-A AVHRR data, Remote Sensing of Environment 112: 3012-3029. http://dx.doi.org/10.1016/j.rse.2008.02.013

Derrien, M.; Le Gléau, H. 2005. MSG/SEVIRI cloud mask and type from SAFNWC, International Journal of Remote Sensing 26: 4707-4732.

http://dx.doi.org/10.1080/01431160500166128

Desbois, M.; Seze, G.; Szejwach, G. 1982. Automatic classification of clouds on METEOSAT imagery: application to high-level clouds, Journal of Applied Meteorology 21: 401-412. http://dx.doi.org/10.1175/15200450(1982)021<0401:ACOCOM>2.0.CO;2

Di Girolamo, L.; Wilson, M. 2003. A first look at band-differenced angular signatures for cloud detection from MISR, Geoscience and Remote Sensing, IEEE Transactions on 41: 1730-1734.

Diner, D.; Davies, R.; DiGirolamo, L.; Horvath, A.; Moroney, C.; Muller, J.; Paradise, S. 2000. Level 2 Cloud Detection and Classification Algorithm Theoretical Basis. Jet Propulsion Laboratory, California Institute of Technology, D-11399, Rev. D. $110 \mathrm{p}$.

Durpaire, J. P.; Gentet, T.; Phulpin, T.; Arnaud, M. 1995. Spot-4 vegetation instrument: vegetation monitoring on a global scale, Acta Astronautica 35: 453-459.

http://dx.doi.org/10.1016/0094-5765(94)00279-U

Feister, U.; Shields, J. 2005. Cloud and radiance measurements with the VIS/NIR Daylight Whole Sky Imager at Lindenberg (Germany), Meteorologische Zeitschrift 14: 627-639. http://dx.doi.org/10.1127/0941-2948/2005/0066

Fensholt, R.; Anyamba, A.; Stisen, S.; Sandholt, I.; Pak, E.; Small, J. 2007. Comparisons of compositing period length for vegetation index data from polar-orbiting and geostationary satellites for the cloud-prone region of West Africa, Photogrammetric Engineering and Remote Sensing 73: 297-309.

Franca, G.; Cracknell, A. 1995. A simple cloud masking approach using NOAA AVHRR daytime data for tropical areas, International Journal of Remote Sensing 16: 1697-1705. http://dx.doi.org/10.1080/01431169508954506

Frey, R. A. 2003. The MODIS cloud products: algorithms and examples from Terra, Ieee Transactions on Geoscience and Remote Sensing 41: 459-473. http://dx.doi.org/10.1109/TGRS.2002.808301

Frey, R. A.; Ackerman, S. A.; Liu, Y.; Strabala, K. I.; Zhang, H.; Key, J. R.; Wang, X. 2008. Cloud detection with MODIS. Part I: improvements in the MODIS cloud mask for Collec- 
tion 5, Journal of Atmospheric and Oceanic Technology 25: 1057-1072. http://dx.doi.org/10.1175/2008JTECHA1052.1

Gesell, G. 1989. An algorithm for snow and ice detection using AVHRR data an extension to the APOLLO software package, International Journal of Remote Sensing 10: 897-905. http://dx.doi.org/10.1080/01431168908903929

German Aerospace Centre (DLR). 2007. Available from Internet: http://wdc.dlr.de:8082/apollo

Girolamo, L.; Davies, R. 1995. The Image navigation cloud mask for the multiangle imaging spectroradiometer (MISR), Journal of Atmospheric and Oceanic Technology 12: 1215-1228. http://dx.doi.org/10.1175/1520-0426(1995)012<1215:TINCMF $>2.0$. CO;2

Gomez-Chova, L.; Gomez-Chova, L.; Camps-Valls, G.; CalpeMaravilla, J.; Guanter, L. A. G. L.; Moreno, J. A. M. J. 2007. Cloud-screening algorithm for ENVISAT/MERIS multispectral images cloud-screening algorithm for ENVISAT/ MERIS multispectral images, Geoscience and Remote Sensing, IEEE Transactions on 45: 4105-4118.

Goodrum, G.; Kidwell, K.; Winston, W.; Aleman, R.; Branch, S. S.; Center, N. C. D. 1999. NOAA KLM User's Guide. US Dept. of Commerce, National Oceanic and Atmospheric Administration.

Haran, T. M.; Fahnestock, M. A.; Scambos, T. A. 2002. De-striping of MODIS optical bands for ice sheet mapping and topography, EOS, Transactions, American Geophysical Union 88(47): F317.

Im, E.; Wu, C.; Durden, S. L. 2005. Cloud profiling radar for the CloudSat mission, in Radar Conference, 2005 IEEE International IEEE, 483-486.

Irish, R. 2000. Landsat 7 automatic cloud cover assessment [4049-35].

Jedlovec, G.; Haines, S.; LaFontaine, F. 2008. Spatial and temporal varying thresholds for cloud detection in GOES imagery, Geoscience and Remote Sensing, IEEE Transactions on 46: $1705-1717$.

Johnson, D.; Flament, P.; Bernstein, R. 1994. High-resolution satellite imagery for mesoscale meteorological studies, Bulletin of the American Meteorological Society 75: 5-33. http://dx.doi. org/10.1175/1520-0477(1994)075<0005:HRSIFM>2.0.CO;2

Karlsson, K. 2003. A 10 year cloud climatology over Scandinavia derived from NOAA advanced very high resolution radiometer imagery, International Journal of Climatology 23: 1023-1044. http://dx.doi.org/10.1002/joc.916

Key, J.; Barry, R. 1989. Cloud cover analysis with Arctic AVHRR data 1. Cloud detection, Journal of Geophysical Research 94(D15): 18521-18535.

http://dx.doi.org/10.1029/JD094iD15p18521

Kidwell, K. 1995. NOAA Polar Orbiter Data Users Guide: (TIROS-N, NOAA-6, NOAA-7, NOAA-8, NOAA-9, NOAA-10, NOAA-11, NOAA-12, NOAA-13, and NOAA-14). National Oceanic and Atmospheric Administration, National Environmental Satellite, Data, and Information Service, National Climatic Data Center, Satellite Data Services Division.

Krebs, W.; Mannstein, H.; Bugliaro, L.; Mayer, B. 2007. Technical note: a new day-and night-time Meteosat Second Generation Cirrus Detection Algorithm MeCiDA, Atmos. Chem. Phys 7: 6145-6159.

http://dx.doi.org/10.5194/acp-7-6145-2007

Kriebel, K. 1990. Cloud analysis with satellite data, ESA-SP, 17.

Kriebel, K. T.; Gesell, G.; Uml, Stner, M.; Mannstein, H. 2003. The cloud analysis tool APOLLO: improvements and validations, International Journal of Remote Sensing 24: 23892408. http://dx.doi.org/10.1080/01431160210163065
Liberti, G. L.; Mezdari, H. E. 2000. Comparison of SPOT cloud cover quality index against meteorological surface observations, International Journal of Remote Sensing 21: 24392461. http://dx.doi.org/10.1080/01431160050030556

Lier, P.; Bach, M. 2008. PARASOL a microsatellite in the A-Train for Earth atmospheric observations, Acta Astronautica 62: 257-263. http://dx.doi.org/10.1016/j.actaastro.2006.12.052

Lissens, G.; Kempeneers, P.; Fierens, F.; Van Rensbergen, J. 2000. Development of cloud, snow, and shadow masking algorithms for VEGETATION imagery, in International Geoscience and Remote Sensing Symposium (IGARSS), 834-836.

Logar, A. M.; Logar, A. M.; Lloyd, D. E.; Corwin, E. M.; Penaloza, M. L. A. P. M. L.; Feind, R. E. A. F. R. E.; Berendes, T. A. A. B. T. A.; Kwo-Sen Kuo, A. K.-S. K.; Welch, R. M. A. W. R. M. 1998. The ASTER polar cloud mask the ASTER polar cloud mask, Geoscience and Remote Sensing, IEEE Transactions on 36: 1302-1312.

Luo, Y.; Trishchenko, A. P.; Khlopenkov, K. V. 2008. Developing clear-sky, cloud and cloud shadow mask for producing clear-sky composites at 250-meter spatial resolution for the seven MODIS land bands over Canada and North America, Remote Sensing of Environment 112: 4167-4185. http://dx.doi.org/10.1016/j.rse.2008.06.010

Menzel, W.; Purdom, J. 1994. Introducing GOES-I: the first of a new generation of geostationary operational environmental satellites, Bulletin of the American Meteorological Society 75: 757-781. http://dx.doi.org/10.1175/1520-0477(1994)075<0757:IGITFO >2.0.CO;2

National Aeronautics and Space Administration. 2011. Available from Internet: http://ladsweb.nascom.nasa.gov/data/ ftp_site.html

Norris, J. 1999. On trends and possible artifacts in global ocean cloud cover between 1952 and 1995, Journal of Climate 12: 1864-1870. http://dx.doi.org/10.1175/1520-0442(1999) $012<1864$ :OTAPAI $>2.0$. CO;2

Platnick, S.; King, M. D.; Ackerman, S. A.; Menzel, W. P.; Baum, B. A.; Riedi, J. C.; Frey, R. A. 2003. The MODIS cloud products: algorithms and examples from terra, Ieee Transactions on Geoscience and Remote Sensing 41: 459-473. http://dx.doi.org/10.1109/TGRS.2002.808301

Plummer, S. 2005. Establishing the GLOBCARBON cloud detection system over land for the along track scanning radiometer (atsr) sensor series, in Proceedings of the MERIS (A) ATSR Workshop 2005, 26-30 Sept. 2005. ESRIN Frascati, Italy, 5.1-5.6.

Rossow, W.; Garder, L. 1993. Cloud detection using satellite measurements of infrared and visible radiances for ISCCP, Journal of Climate 6: 2341-2369. http://dx.doi.org/10.1175/15200442(1993)006<2341:CDUSMO > 2.0.CO;2

Rossow, W.; Schiffer, R. 1991. ISCCP cloud data products, Bulletin of the American Meteorological Society 72: 2-20. http://dx.doi.org/10.1175/1520-0477(1991) 072<0002:ICDP >2.0.CO;2

Rossow, W. B.; Walker, A. W.; Garder, L. C. 1993. Comparison of ISCCP and other cloud amounts, Journal of Climate 6: 2394-2418. http://dx.doi.org/10.1175/1520-0442(1993)006<2394:COIAOC $>2.0$. CO;2

Roy, D. 2000. The impact of misregistration upon composited wide field of viewsatellite data and implications for change detection, Geoscience and Remote Sensing, IEEE Transactions on 38: 2017-2032.

Santer, R.; Carrere, V.; Dessaily, D.; Dubuisson, P.; Roger, J. 2000. MERIS ATBD 2.15: algorithm theoretical basis document, atmospheric correction over land. Technical report PO-TN-MEL-GS-0005, LISE. 
Sassen, K.; Wang, Z. 2008. Classifying clouds around the globe with the CloudSat radar: 1-year of results, Geophysical Research Letters 35.

Schaaf, C. B.; Gao, F.; Strahler, A. H.; Lucht, W.; Li, X.; Tsang, T.; Strugnell, N. C.; Zhang, X.; Jin, Y.; Muller, J.-P.; Lewis, P.; Barnsley, M.; Hobson, P.; Disney, M.; Roberts, G.; Dunderdale, M.; Doll, C.; d’Entremont, R. P.; Hu, B.; Liang, S.; Privette, J. L.; Roy, D. 2002. First operational BRDF, albedo nadir reflectance products from MODIS, Remote Sensing of Environment 83: 135-148.

http://dx.doi.org/10.1016/S0034-4257(02)00091-3

Schreiner, A.; Unger, D.; Menzel, W.; Ellrod, G.; Strabala, K.; Pellet, J. 1993. A comparison of ground and satellite observations of cloud cover, Bulletin of the American Meteorological Society 74: 1851-1861. http://dx.doi.org/10.1175/15200477(1993)074<1851:ACOGAS >2.0.CO;2

Shin, D.; Pollard, J.; Muller, J. 1996. Cloud detection from thermal infrared images using a segmentation technique, International Journal of Remote Sensing 17: 2845-2856. http://dx.doi.org/10.1080/01431169608949110

Simpson, J. J.; Gobat, J. I. 1995. Improved cloud detection in GOES scenes over land, Remote Sensing of Environment 52: 36-54. http://dx.doi.org/10.1016/0034-4257(94)00080-7

Simpson, J. J.; Tsou, Y. L.; Schmidt, A.; Harris, A. 2005. Analysis of along track scanning radiometer-2 (ATSR-2) data for clouds, glint and sea surface temperature using neural networks, Remote Sensing of Environment 98: 152-181. http://dx.doi.org/10.1016/j.rse.2005.05.022

Spinhirne, J.; Hart, W.; Hlavka, D. 1996. Cirrus infrared parameters and shortwave reflectance relations from observations, Journal of the Atmospheric Sciences 53: 1438-1458. http://dx.doi.org/10.1175/1520-0469(1996) 053<1438:CIPASR > 2.0.CO;2

Stephens, G.; Vane, D.; Boain, R.; Mace, G.; Sassen, K.; Wang, Z.; Illingworth, A.; O'Connor, E.; Rossow, W.; Durden, S. 2002. The cloudsat mission and the A-train, Bulletin of the American Meteorological Society 83: 1771-1790.

http://dx.doi.org/10.1175/BAMS-83-12-1771

Stowe, L. L.; Davis, P. A.; McClain, E. P. 1999. Scientific basis and initial evaluation of the CLAVR-1 global clear cloud classification algorithm for the advanced very high resolution radiometer, Journal of Atmospheric and Oceanic Technology 16: 656-681. http://dx.doi.org/10.1175/1520-0426(1999)016<0656:SBAIEO >2.0.CO;2

Stowe, L. L.; Vemury, S. K.; Rao, A. V. 1994. AVHRR clear-sky radiation data sets at NOAA/NESDIS, Advances in Space Research 14: 113-116.

http://dx.doi.org/10.1016/0273-1177(94)90358-1

Strabala, K. I. 2005. MODIS cloud mask user's guide. University of Wisconsin--Madison. Space Science and Engineering.

Stubenrauch, C.; Briand, V.; Rossow, W. 2002. The role of clear-sky identification in the study of cloud radiative effects: combined analysis from ISCCP and the scanner of radiation budget, Journal of Applied Meteorology 41: 396-412. http://dx.doi.org/10.1175/1520-0450(2002)041<0396:TROCSI>2.0.CO;2

Town, M.; Walden, V.; Warren, S. 2007. Cloud cover over the South Pole from visual observations, satellite retrievals, and surface-based infrared radiation measurements, Journal of Climate 20: 544-559. http://dx.doi.org/10.1175/JCLI4005.1

Turner, D.; Ackerman, S.; Baum, B.; Revercomb, H.; Yang, P. 2003. Cloud phase determination using ground-based AERI observations at SHEBA, Journal of Applied Meteo- rology 42: 701-715. http://dx.doi.org/10.1175/1520-0450(2003)042<0701:CPDUGA > 2.0.CO;2

Van Lammeren, A.; Feijt, A.; Konings, J.; Van Meijgaard, E.; Van ulden, A. 2000. Combination of ground-based and satellite cloud observations on a routine basis, Meteorologische Zeitschrift (Stuttgart) 9: 125-134.

Vant-Hull, B.; Marshak, A.; Remer, L.; Li, Z. 2007. The effects of scattering angle and cumulus cloud geometry on satellite retrievals of cloud droplet effective radius, Ieee Transactions on Geoscience and Remote Sensing 45: 1039.

http://dx.doi.org/10.1109/TGRS.2006.890416

Wielicki, B.; Barkstrom, B.; Harrison, E.; Lee III, R.; Louis Smith, G.; Cooper, J. 1996. Clouds and the Earth's Radiant Energy System (CERES): an Earth observing system experiment, Bulletin of the American Meteorological Society 77: 853-868. http://dx.doi.org/10.1175/1520-0477(1996)077<0853:CATERE>2.0.CO;2

Wielicki, B.; Baum, B.; Charlock, B.; Green, T.; Kratz, R.; Lee, D.; Minnis, R.; Smith, P.; Young, G.; Cess, D. 1998. Clouds and the Earth's Radiant Energy System (CERES): algorithmoverview, Geoscience and Remote Sensing, IEEE Transactions on 36: 1127-1141.

Winker, D.; Hunt, W.; McGill, M. 2007. Initial performance assessment of CALIOP, Geophys. Res. Lett 34.

Wylie, D.; Jackson, D.; Menzel, W.; Bates, J. 2005. Trends in global cloud cover in two decades of HIRS observations, Journal of Climate 18: 3021-3031.

http://dx.doi.org/10.1175/JCLI3461.1

Yang, Y.; Di Girolamo, L.; Mazzoni, D. 2007. Selection of the automated thresholding algorithm for the multi-angle imaging spectroradiometer radiometric camera-by-camera cloud mask over land, Remote Sensing of Environment 107: 159-171. http://dx.doi.org/10.1016/j.rse.2006.05.020

Young, D.; Minnis, P.; Baumgardner, D.; Gerber, H. 1998. Comparison of in situ and satellite-derived cloud properties during SUCCESS (Paper 98GL00116), Geophysical Research Letters 25: 1125-1128. http://dx.doi.org/10.1029/98GL00116

Zavody, A. M.; Mutlow, C. T.; Llewellyn-Jones, D. T. 2000. Cloud clearing over the ocean in the processing of data from the along-track scanning radiometer (ATSR), Journal of Atmospheric and Oceanic Technology 17: 595-615. http://dx.doi. org/10.1175/1520-0426(2000)017<0595:CCOTOI>2.0.CO;2

Zhang, H.; Frey, R.; Ackerman, S.; Gumley, L.; Strabala, K.; Menzel, W. 2003. MODIS cloud mask: current situation and its improvements, in SPIE-International Society for Optical Engineering, Bellingham, WA, 236-241.

Zhang, J. H.; Lohmann, U. 2003. Sensitivity of single column model simulations of Arctic springtime clouds to different cloud cover and mixed phase cloud parameterizations, Journal of Geophysical Research-Atmospheres 108.

$\overline{\text { Ebenezer Yemi OGUNBADEWA. Ph.D. He is presently a se- }}$ nior lecturer in remote sensing (RS) and geographical information systems (GIS) at Adekunle Ajasin University, Akungba Ondo-State, Nigeria. He obtained B.Sc Geography (University of Ilorin), M. Sc Geography and Planning (University of Lagos) in Nigeria, UN/SIDA International certificate in RS and GIS (University of Stockholm) Sweden and PhD in RS and GIS (University of Salford), UK. He has got many international academic awards and publications in reputable books and scholarly journals.

Research interests: remote sensing, GIS. 